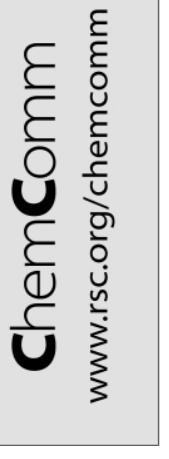

\title{
Cyanide-bridged Fe(III)-Co(II) bis double zigzag chains with a slow relaxation of the magnetisation $\dagger$
}

\author{
Luminita Marilena Toma, ${ }^{a}$ Rodrigue Lescouëzec, ${ }^{a}$ Francesc Lloret, ${ }^{a}$ Miguel Julve, ${ }^{* a}$ Jacqueline \\ Vaissermann $^{b}$ and Michel Verdaguer ${ }^{b}$ \\ a Departament de Química Inorgànica/Instituto de Ciencia Molecular, Facultat de Química de la Universitat \\ de València, Avda. Dr. Moliner 50, 46100-Burjassot (València), Spain \\ ${ }^{b}$ Laboratoire de Chimie Inorganique et Matériaux Moléculaires, Unité CNRS 7071, Université Pierre et \\ Marie Curie, 4 Place Jussieu, Case 42, 75252 Paris Cedex 05, France
}

Received (in Cambridge, UK) 24th February 2003, Accepted 20th May 2003

First published as an Advance Article on the web 27th June 2003

Reaction of $\left[\mathrm{Fe}^{\mathrm{III}}(\mathrm{bipy})(\mathrm{CN})_{4}\right]^{-}$with fully solvated $\mathrm{MII}^{\mathrm{II}}$ cations $[\mathrm{M}=\mathrm{Co}(1)$ and $\mathrm{Mn}(2)]$ produces the isostructural bis double chains $\left[\left[\mathrm{Fe}^{\mathrm{III}}(\text { bipy })(\mathrm{CN})_{4}\right]_{2} \mathrm{MI}^{\mathrm{II}}\left(\mathrm{H}_{2} \mathrm{O}\right)\right] \cdot \mathrm{MeCN} \cdot \frac{1}{2} \mathrm{H}_{2} \mathrm{O} ; 1$ exhibits intrachain ferromagnetic and interchain antiferromagnetic couplings, slow magnetic relaxation and hysteresis effects.

One of the fields developing rapidly in the area of molecular magnetic materials is the chemistry and physics of molecular systems with a slow relaxation of the magnetisation. Their interest is twofold: (a) fundamental, since classical properties of macroscopic magnets coexist with quantum effects (tunnelling of magnetisation, quantum phase interference; ${ }^{1,2}$ (b) applied, since they can lead to the ultimate density-molecular-of magnetic information storage and quantum calculations. ${ }^{3}$ They are often named, "single molecule magnets" (SMMs). ${ }^{4}$

A one-dimensional class, of slow relaxing magnetisation compounds appeared more recently, named either magnetic nanowires 5,6 or single-chain magnets: ${ }^{7}$ one ferrimagnetic cobalt(II)-organic radical chain, ${ }^{5}$ two ferromagnetic bimetallic $\mu$-cyano $\mathrm{Fe}(\mathrm{III})-\mathrm{Co}(\mathrm{II})$ double chains, ${ }^{6}$ and a ferrimagnetic Mn(III)-Ni(II) chain. ${ }^{7}$ The anisotropy energy barrier is higher than in the SMMs, reaching values around $150 \mathrm{~K},{ }^{5-7}$ increasing the hope of magnetic information storage at reasonable temperatures.

Using the stable low spin iron(III) $\left[\mathrm{Fe}^{\mathrm{III}}(\text { bipy })(\mathrm{CN})_{4}\right]^{-}$as a ligand, ${ }^{8}$ we obtained two new isostructural bimetallic chains, $\left[\left\{\mathrm{Fe}^{\mathrm{III}}(\text { bipy })(\mathrm{CN})_{4}\right\}_{2} \mathrm{MI}^{\mathrm{II}}\left(\mathrm{H}_{2} \mathrm{O}\right)\right] \cdot \mathrm{MeCN} \cdot 0.5 \mathrm{H}_{2} \mathrm{O}[\mathrm{M}=\mathrm{Co}(\mathbf{1})$ and $\mathrm{Mn}(2)$; bipy $=2,2^{\prime}$-bipyridine], which result from the condensation of two double zigzag chains ${ }^{6}$ and whose structure and preliminary magnetic investigation are presented here.

Single crystals of $\mathbf{1}$ and $\mathbf{2}$ were grown in a $\mathrm{MeCN}: \mathrm{H}_{2} \mathrm{O} 90$ : $10(\mathrm{v} / \mathrm{v})$ mixture by a slow-diffusion method using an $\mathrm{H}-$ double-tube glass vessel in the dark. The starting solutions were solutions of $\mathrm{PPh}_{4}\left[\mathrm{Fe}(\right.$ bipy $\left.)(\mathrm{CN})_{4}\right] \cdot \mathrm{H}_{2} \mathrm{O}(0.05 \mathrm{mmol})$ in one arm and of $\mathrm{Co}\left(\mathrm{NO}_{3}\right)_{2} \cdot 6 \mathrm{H}_{2} \mathrm{O}(\mathbf{1})$ or $\mathrm{Mn}\left(\mathrm{NO}_{3}\right)_{2} \cdot 4 \mathrm{H}_{2} \mathrm{O}(2)(0.1 \mathrm{mmol})$ in the other one. After a few weeks orange plates (1) and red prisms (2) were formed together with an unidentified dark green powder. The crystals were collected and dried on filter paper. Yield: $c a$. $20 \%$ for $\mathbf{1}$ and $\mathbf{2}$. $\neq$

$\mathbf{1}$ and $\mathbf{2}$ are isostructural. $\$$ Their structure is made up of neutral one-dimensional $\left[\left\{\mathrm{Fe}(\text { bipy })(\mathrm{CN})_{4}\right\}_{2} \mathrm{M}\left(\mathrm{H}_{2} \mathrm{O}\right)\right]$ units running parallel to the $b$ axis (Fig. 1, top) and crystallisation water and $\mathrm{MeCN}$ molecules. The crystallographically independent unit (Figs. S1 and S2) † contains two types of iron $[\mathrm{Fe}(1)$ and $\mathrm{Fe}(2)]$ and one cobalt $[\mathrm{Co}(1), 1]$ or manganese $[\mathrm{Mn}(1), 2]$ atoms, the latter being connected to five iron atoms through cyanide bridges (Fig. 1, bottom). This leads to a corrugated ladder-like chain with regular alternating $\mathrm{Fe}(1)$ and $\mathrm{M}(1)$ atoms along the edges. Each rung is defined by an $\mathrm{Fe}-\mathrm{M}$ pair, where

$\dagger$ Electronic supplementary information (ESI) available: perspective views of the asymmetric units of $\mathbf{1}$ and $\mathbf{2}$ with the atom numbering (Figs. S1 and $\mathrm{S} 2$ ); a plot of the temperature dependence of $\chi_{\mathrm{M}} T$ for 2 (Fig. S3); and a summary of the main bond lengths and angles for $\mathbf{1}$ and $\mathbf{2}$. See http:// www.rsc.org/suppdata/cc/b3/b302182n/ each pair of adjacent $\mathrm{M}$ atoms is connected through iron [Fe(2)]. A cyano group bridges each $\mathrm{Fe}-\mathrm{M}$ pair. The two crystallographically independent iron atoms $(\mathrm{Fe}(1)$ and $\mathrm{Fe}(2))$ exhibit the same distorted octahedral surrounding $\mathrm{FeN}_{2} \mathrm{C}_{4}$ as in previous reports. ${ }^{6,8}$ The difference between $[\mathrm{Fe}(1)(\mathrm{bi}-$ py) $\left.(\mathrm{CN})_{4}\right]^{-}$and $\left[\mathrm{Fe}(2)(\text { bipy })(\mathrm{CN})_{4}\right]^{-}$is that the former acts as a trismonodentate ligand toward the $\mathrm{M}$ atoms through three cyanides in $f a c$ position whereas the latter adopts a bismonodentate coordination mode (two cyanides in cis position). The $\mathrm{M}$ atom is six-co-ordinated with five cyanide-nitrogen atoms and a water molecule forming a distorted $\mathrm{MN}_{5} \mathrm{O}$ octahedron.

The value of the dihedral angle between adjacent mean planes of the corrugated ladder-like motif is $90^{\circ}$ [angle at the $\mathrm{Fe}(1) \cdots \mathrm{M}$ (c) hinge in Fig. 1 (bottom)], whereas those between the $\mathrm{Fe}(1) \mathrm{MM}(\mathrm{a})$ plane and $\mathrm{Fe}(1) \mathrm{M}(\mathrm{a}) \mathrm{Fe}(1 \mathrm{c}) \mathrm{M}(\mathrm{c})$ and $\mathrm{Fe}(1) \mathrm{M}-$ $\mathrm{Fe}(1 \mathrm{~d}) \mathrm{M}(\mathrm{c})$ mean planes are 87 and $93^{\circ}(\mathbf{1}$ and $\mathbf{2})$. The values of the $\mathrm{Fe} \cdot \mathrm{M}$ distances vary between $4.963(1)$ and 5.217(1) A for 1 and 5.007(1) and 5.313(1) $\AA$ for 2. The shortest interchain metal-metal separations are 8.085(1) (1) and 8.090(1) А (2) $[\mathrm{Fe}(2) \cdots \mathrm{Fe}(2 \mathrm{e}) ;(\mathrm{e})=1-x,-y, 2-z]$. The acetonitrile molecule is well isolated in the structure whereas hydrogen bonds link the coordinated and crystallization water molecules $[\mathrm{O}(10) \cdots \mathrm{O}(1)=2.39(2)(\mathbf{1})$ and $2.43(2) \AA(\mathbf{2})]$ and the

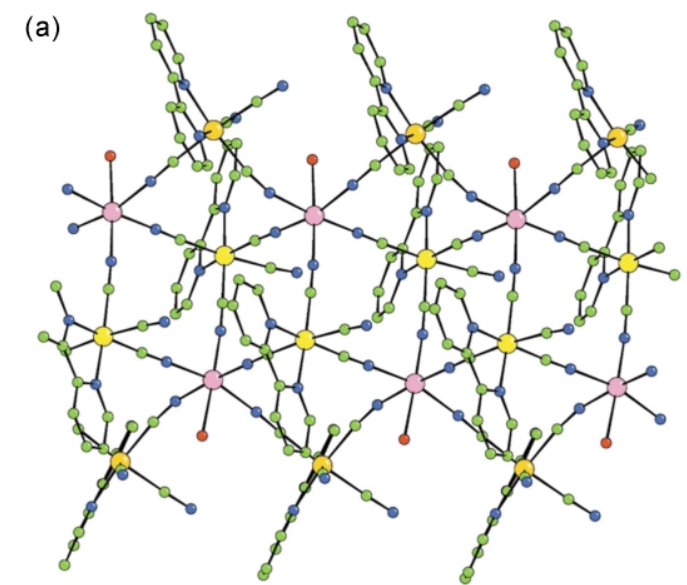

(b)

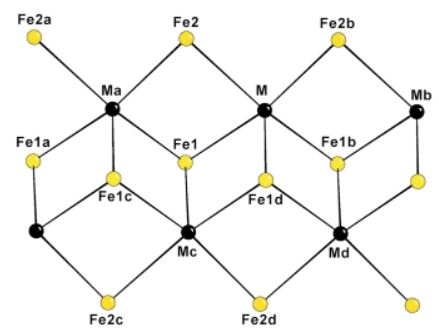

Fig. 1 Top: A view of the structure of $\mathbf{1}$ and $\mathbf{2}$ along the $b$ axis. Solvent and hydrogen atoms are omitted. The metals are yellow (Fe) and pink [Co (1) or Mn (2)]. Bottom: Schematic view of the metallic frame of $\mathbf{1}(\mathrm{M}=\mathrm{Co})$ and $2(\mathrm{M}=\mathrm{Mn})$. Selected bond lengths and angles are in Table S1 in ESI. $\dagger$ 
crystallization water and one of the terminal cyanide nitrogens $[\mathrm{O}(10) \cdots \mathrm{N}(8 \mathrm{~b})=3.00(2)(\mathbf{1})$ and 2.97(1) $\AA(\mathbf{2})]$.

The thermal variation of $\chi_{\mathrm{M}} T$ per $\mathrm{Fe}^{\mathrm{III}}{ }_{2} \mathrm{Co}^{\mathrm{II}}$ unit of a powder sample of 1 is shown in Fig. 2. At room temperature, $\chi_{\mathrm{M}} T$ is equal to $5.0 \mathrm{~cm}^{3} \mathrm{~mol}^{-1} \mathrm{~K}$, which corresponds to one high spin $\mathrm{Co}$ (II) $\left(S_{\mathrm{Co}}=\frac{3}{2}\right)$ and two low spin $\mathrm{Fe}(\mathrm{III})\left(S_{\mathrm{Fe}}=\frac{1}{2}\right)$ ions with significant orbital contributions. Upon cooling, $\chi_{\mathrm{M}} T$ increases smoothly in a monotonous way [in line with an intrachain ferromagnetic coupling between $\mathrm{Co}$ (II) and $\mathrm{Fe}(\mathrm{III})]$ until $T<50$ $\mathrm{K}$ where it sharply increases to reach a maximum of $c a .94 \mathrm{~cm}^{3}$ $\mathrm{mol}^{-1} \mathrm{~K}$ at $10 \mathrm{~K}$ and further decreases with $T$ (as the magnetisation becomes field dependent). A maximum of susceptibility is observed around $7 \mathrm{~K}$ for applied fields lower than $600 \mathrm{G}$ (Fig. 2, top, inset), a sign of a weak antiferromagnetic coupling between ferromagnetic entities. The maximum disappears for $H>600 \mathrm{G}$, suggesting a fieldinduced transition from an antiferromagnetic to a ferromagnetic ground state. This magnetic behaviour is consistent with the structure of 1 . The sigmoidal shape of the $M$ versus $H$ plot at 2 $\mathrm{K}$ (Fig. 2, bottom) agrees with a metamagnetic behaviour. The magnetic energy for $H=600 \mathrm{G}$ is $c a .0 .06 \mathrm{~cm}^{-1}$ and gives the order of magnitude of the antiferromagnetic interchain interaction. In an applied field above $600 \mathrm{G}$, the interchain interaction is overcome and $\mathbf{1}$ behaves as ferromagnetic $\mathrm{Fe}^{\mathrm{III}}{ }_{2} \mathrm{Co}^{\mathrm{II}}$ chains. The lack of $\lambda$-peak in the heat capacity measurements on powder samples of $\mathbf{1}$ in the temperature range $290-1.8 \mathrm{~K}$ both at $H=0$ and $800 \mathrm{G}$, is a strong indication of the absence of three-dimensional magnetic order in 1 . The magnetisation at saturation per $\mathrm{Fe}^{\mathrm{III}}{ }_{2} \mathrm{Co}^{\mathrm{II}}$ unit, at $2 \mathrm{~K}$ and $5 \mathrm{~T}$, is $M_{\mathrm{S}}=4.1 \mu \mathrm{B}\left[\mathrm{ca} .1 \mu \mathrm{B}\right.$ per Fe ${ }^{\mathrm{III}}$ and about $2 \mu \mathrm{B}$ per $\mathrm{Co}^{\mathrm{II}}$

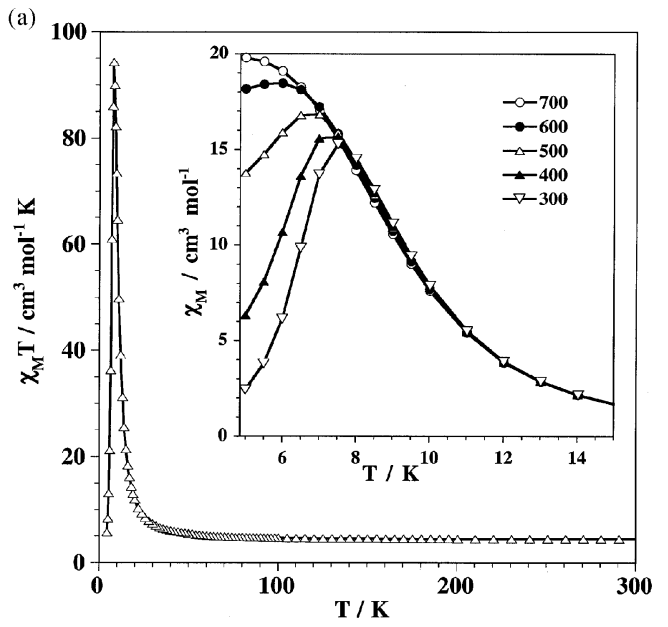

(b)

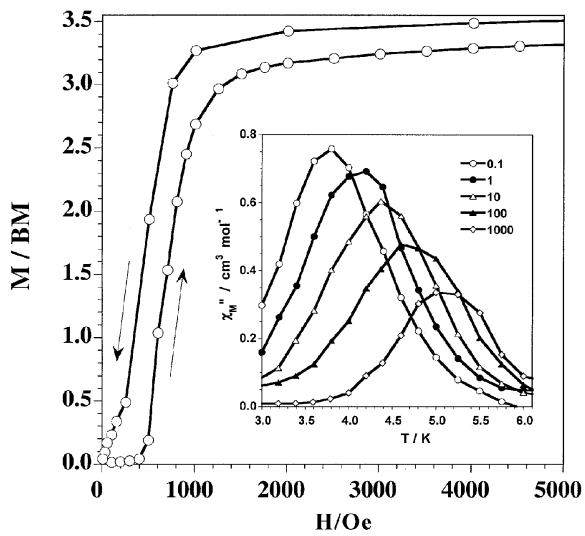

Fig. 2 Magnetic behaviour of 1. Top: Temperature dependence of $\chi_{\mathrm{M}} T$ per $\mathrm{Fe}^{\mathrm{III}}{ }_{2} \mathrm{Co}^{\mathrm{II}}$ unit under an applied magnetic field of $100 \mathrm{G}$. The solid line is an eye guide. The inset shows the field dependence of the magnetic susceptibility. Bottom: Magnetisation $v s . H$ plot at $2 \mathrm{~K}$. Inset: $\chi^{\prime \prime}$ ac susceptibility [1 G oscillating field $(0.1-1000 \mathrm{~Hz}), 800 \mathrm{G}$ applied dc field]. (assuming an effective $S_{\mathrm{Co}}=\frac{1}{2}$ and $g_{\mathrm{Co}}=4$ )], in agreement with an intrachain ferromagnetic coupling. The magnetic behaviour of 1 above $H \geq 600 \mathrm{G}$ is similar to that of the $\mathrm{Fe}^{\mathrm{III}}{ }_{2} \mathrm{Co}{ }^{\mathrm{II}}$ double zigzag chains, ${ }^{5}$ which exhibit slow magnetic relaxation and hysteresis effects not associated with a threedimensional magnetic order. The frequency dependence of the out-of-phase component $\left(\chi_{\mathrm{M}}{ }^{\prime \prime}\right)$ of the molar ac susceptibility of 1 under an applied field of $800 \mathrm{G}$ is shown in Fig. 2. Between 2 and $7 \mathrm{~K}$, the relaxation times follow an Arrhenius law $\left[\tau=\tau_{0}\right.$ $\left.\exp \left(E_{\mathrm{a}} / k_{\mathrm{B}} T\right)\right]$ with $E_{\mathrm{a}} / k_{\mathrm{B}}=152 \mathrm{~K}$ and $\tau_{0}=1.5 \times 10^{-17} \mathrm{~s}$. The energy barrier $E_{\mathrm{a}} / k_{\mathrm{B}}$ is close to those found in the previous nanowires. ${ }^{5-7}$ Instead, the $\tau_{0}$ prefactor is much smaller: obtained under an applied magnetic field, it deserves more study.

The magnetic behaviour of $\mathbf{2}$ (susceptibility and magnetisation at $2 \mathrm{~K}$, Fig. S3) is the one of two ferrimagnetic $\mathrm{Fe}_{2} \mathrm{Mn}$ chains coupled by a weak antiferromagnetic interaction.

The flexibility of the system allows the substitution of $\mathrm{Fe}$ and $\mathrm{M}$ by other metal ions, the replacement of bipy by other chelating ligands and the tailoring of new cyanide-bridged architectures and magnetic properties. Indeed, our new example of magnetic nanowire demonstrates the possibility of expanding the range of slow magnetic relaxing materials. The Glauber's model $^{9}$ is probably too simple to fully describe the new magnetic behaviours.

This research was supported by the Spanish Ministry of Science and Education (Project BQU2001-2928), the French Ministry of Education Nationale, the TMR Programme of the European Union (Contract ERBFMRXCT-98-0181) and the European Science Foundation (Molecular Magnets Programme). One of us (L. M. Toma) thanks the Spanish Ministry of Education for an FPU predoctoral grant.

\section{Notes and references}

$\ddagger$ Characterisation of $\mathbf{1}$ and 2: IR (solid, $\mathrm{KBr}$ pellets), $v_{\mathrm{CN}} 2160,2149$ and 2115 (1) and 2152, 2143 and $2114 \mathrm{~cm}^{-1}$ (2). Elemental analysis $(\mathrm{C}, \mathrm{H}, \mathrm{N})$ is in agreement with their formulae.

$\$$ Crystal and structure refinement parameters for $\mathbf{1}$ and 2. Compound 1: $\mathrm{C}_{30} \mathrm{H}_{22} \mathrm{Fe}_{2} \mathrm{CoN}_{13} \mathrm{O}_{1.5}, T=295 \mathrm{~K}, P 2_{1} / n, Z=4, a=19.848(7) \AA ⿻$ $7.365(2) \AA, c=21.143(7) \AA, \beta=96.67(3)^{\circ}, V=3070(2) \AA^{3}, d_{\text {calc }}=1.64$ $\mathrm{g} \mathrm{cm}^{-3}, R_{1}=0.0367, w R_{2}=0.0449$. Compound 2: $\mathrm{C}_{30} \mathrm{H}_{22} \mathrm{Fe}_{2} \mathrm{MnN}_{13} \mathrm{O}_{1.5}$, $T=295 \mathrm{~K}, P 2_{1} / n, Z=4, a=19.956(5) \AA, b=7.464(3) \AA, c=21.215(5)$ $\AA, \beta=96.42(3)^{\circ}, V=3140(1) \AA^{3}, d_{\text {calc }}=1.60 \mathrm{~g} \mathrm{~cm}^{-3}, R_{1}=0.0406, w R_{2}$ $=0.0494$. Data were collected on a CAD-4 Enraf-Nonius diffractometer with graphite-monochromated Mo K $\alpha$ radiation $(\lambda=0.71069 \AA)$, and were corrected for Lorentz, polarisation and absorption effects. The structures were solved by direct methods through SHELXS-86 and subsequently refined by Fourier recycling. The residual maxima and minima in the final Fourier difference maps were 0.57 and -0.47 e $\AA^{-3}$ for 1 and 0.69 and -0.57 e $\AA^{-3}$ for 2. CCDC 204864 (1) and 204865 (2). See http:// www.rsc.org/suppdata/cc/b3/b302182n/ for crystallographic data in .cif format.

1 (a) L. Thomas, F. Lionti, R. Ballou, D. Gatteschi, R. Sessoli and B Barbara, Nature, 1996, 383, 145; (b) J. R. Friedman, M. P. Sarachik, J. Tejada and R. Ziolo, Phys. Rev. Lett., 1996, 76, 3830; (c) W. Wernsdorfer, N. Aliaga-Alcalde, D. N. Hendrickson and G. Christou, Nature, 2002, 416, 406.

2 W. Wernsdorfer and R. Sessoli, Science, 1999, 284, 133

3 N. Leuenberger and D. Loss, Nature, 2001, 410, 789.

4 D. Gatteschi and R. Sessoli, Angew. Chem., Int. Ed., 2003, 42, 268.

5 A. Caneschi, D. Gatteschi, C. S. Lalioti, R. Sessoli, G. Venturi, A. Vindigni, A. Rettori, M. G. Pini and M. A. Novak, Angew. Chem., Int. Ed., 2001, 40, 1760.

6 R. Lescouëzec, J. Vaissermann, C. Ruiz-Pérez, F. Lloret, R. Carrasco, M. Julve, M. Verdaguer, Y. Dromzée, D. Gatteschi and W. Wernsdorfer, Angew. Chem., Int. Ed., 2003, 42, 1430.

7 R. Clérac, H. Miyasaka, M. Yamashita and C. Coulon, J. Am. Chem. Soc., 2002, 124, 12837

8 L. M. Toma, R. Lescouëzec, L. D. Toma, F. Lloret, M. Julve, J. Vaissermann and M. Andruh, J. Chem. Soc., Dalton Trans., 2002, 3171 and references therein.

9 R. J. Glauber, J. Math. Phys., 1963, 4, 294. 